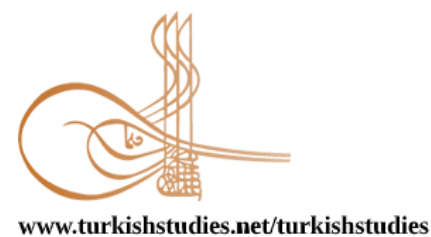

Turkish Studies

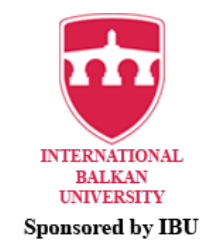

\title{
WhatsApp'ta Yayılan COVID-19 Mesajları Zincir Mektupların Yeni ve Farklı Bir Biçimi Olabilir mi?
}

\author{
Could the COVID-19 Messages Spread on Whatsapp be a New and Different Form of Chain \\ Letters?
}

\author{
Hasan Kızıldağ $\breve{~}^{*}$
}

\begin{abstract}
Chain letters are texts sent by any person, addressed to the recipient by transmitting a specific story, and demanding that the recipient follow certain instructions and that the content sent to him or her be reproduced and sent to others. The chain letters, written in many different forms and contents since their emergence, make their recipients promise "luck and money, pray, happiness, peace", enabling the text to be reproduced and sent to a certain number of people over a certain period. Chain letters are texts that warn about bad luck if the instructions are not followed. Chain letters, while being distributed by writing in traditional ways, evolved into chain e-mails with the advent of computers and the internet, and later, chain letters that were often shared in social media such as Facebook and Twitter emerged. The last area of propagation of chain letters has been the instant communication app WhatsApp. Chain letters, which can be described as contemporary/urban legends, have also benefited from the speed and anonymity of the internet, becoming more common than ever before in history. At the end of 2019 in Wuhan, China, COVID-19 disease has become a global pandemic and a period of the peak for chain letters. The chain letters, fed by the danger and obscurity of the epidemic, have become very quickly sent from person to person around the world via WhatsApp, an instant communication application. In this study, based on the hypothesis that the messages spread in relation to the COVID-19 pandemic on WhatsApp are a new and different form of chain letters, examined the similarities and differences between these messages and the traditional chain letters and whether these messages. By analyzing four widely shared audio recordings and three text messages related to the COVID-19 pandemic, the characteristics of the next generation of chain letters have been revealed.
\end{abstract}

Structured Abstract: Chain letters are texts sent by any person, addressing the recipient by conveying a specific story, and demanding that the recipient follow certain instructions. The main reason for the existence of these anonymous letters is that they are delivered to as many people as possible. The elements of folk culture that it contains, the events that are alleged to have taken place, the texts with the names of real people and places from time to time, "what if it's real?" by using its motive, it has spread throughout the world in many forms and contents. Chain letters are texts that date from the nineteenth century to the present day, spreading through contact with people's different points of sensitivity on a variety of subjects. With the development of technology, chain letters, which found new spreading areas, were transferred from the written culture stage to the secondary orality culture stage along with the internet and gained greater spreading speed. The chain letters that proliferate throughout its historical journey have spread from a

\footnotetext{
* Arş. Gör., Ondokuz Mayıs Üniversitesi Fen-Edebiyat Fakültesi Türk Dili ve Edebiyatı Bölümü Res. Asst, Ondokuz Mayis University, Faculty of Art and Science, Department of Turkish Language and Literature ORCID 0000-0001-7266-6678

kizildaghasan@yandex.com

Cite as/ Atıf: Kızıldağ, H. (2020). WhatsApp'ta yayılan COVID-19 mesajları zincir mektupların yeni ve farklı bir biçimi olabilir mi?. Turkish Studies, 15(4), 667-678. https://dx.doi.org/10.7827/TurkishStudies.44181

Received/Geliş: 12 June/Haziran 2020

Accepted/Kabul: 10 August/Ağustos 2020

Copyright (C) MDE, Turkey
} 
restricted space in a traditional form of letters to people. Then, chain letters spread to with the internet and such as among email users, global social media such as Facebook and Twitter, and finally to people around the world using WhatsApp application. At the end of 2019, the COVID-19 disease in Wuhan, China, spread all over the world and has become one of the most common issues people share with their environment on WhatsApp, where daily communication is the most intense, as it is a disease and danger for all mankind. The problem examined in this study is whether the many audio recordings and texts shared with their environment by people on WhatsApp are an up-to-date and different version of "chain letters". In this study, COVID-19 messages sent over WhatsApp matched the characteristics of the chain letters, and the reasons for the chain effect of the messages were determined. The hypothesis that "messages related to the COVID-19 pandemic shared on WhatsApp are a new and different form of chain letters" put forward in this study has been evaluated in the light of the data. Chain letters are contemporary legends of modern times. The anonymous stories told in these letters attract attention in the community and are largely conveyed through mass media, as well as being narrated as healers. These contemporary myths are now spreading to people and their circles through WhatsApp as well. There are also some differences between COVID-19 chain letters circulating on WhatsApp and chain letters sent either in writing or via email. The WhatsApp chain letters related to coronavirus are more defined as "sharing a reality about the pandemic, revealing the hidden facts, warning people, informing them that the disease has entered a country and passing measures to protect them from this pandemic". In addition to this, both traditional chain letters and chain letters spread on WhatsApp to recipients include pleading words such as "please, attention, send to loved ones, broadcast to everyone, do not be insensitive." Warnings about helping a sick child in traditional chain letters, or about the chance to come if the letter is duplicated and sent to others, or otherwise jinx, are not included in chain letters on WhatsApp. In addition, the new generation of chain letters does not include the instruction that the letter must be transmitted within a specified period of time. The next generation of chain letters is mobilizing people more in the axis of fear. In traditional chain letters, promises and instructions such as "spreading the last words of a dying person, delivering the letter to cover the costs of treating a sick child, the duplicated letter will bring luck and money" have been replaced by absolute "fear" and the instinct to protect their loved ones. The chain letters as contemporary legends are spread by fueling the community's sense of fear by referring to real people, places, and events. Chain letters, of which the first sender is not known, have been found to have certain common characteristics. These:

Be associated with a current hazard or problem,

Triggering fear and survival instinct,

Willingness to protect others,

The sender of the message is from family or friends,

The recipients agree that the sender thinks the message makes sense,

It is seen as a social responsibility to spread the message to others,

Although the message becomes anonymous as the first sender becomes uncertain over time, the identity of the forwarder is clear and the sender and receiver are in a mutual relationship.

Since the spread of COVID-19 messages circulating on WhatsApp has reached serious global heights, company officials have put limits on the transmission of messages. WhatsApp, in the first place, blocked the transmission of an unlimited number of messages, stating that a message could be transmitted to up to five people or groups simultaneously. Then the number of transmissions was restricted to a maximum of one message. In this respect, COVID-19 messages can be sent easily on the internet and especially on WhatsApp, hidden behind the mask of anonymity. However, it is also observed that messages about COVID19 are localized through translation and reshaping across languages. Recently, as the COVID-19 pandemic has affected the whole world and receiving news is of great importance, chain letters have spread throughout the world at a time when uncertainty about the COVID-19 pandemic is growing. In this study, the messages related to the COVID-19 pandemic on WhatsApp were examined using four separate audio recordings and three different texts that spread in this medium, based on the claim that it was a new and different form of chain letters. The audio recordings and texts spread on WhatsApp have been found to have features that are common and different from traditional chain letters. It has been seen how chain letters, which can be described as contemporary legends, are fed and spread from a current and worldwide pandemic. The fact that WhatsApp has limited the number of message transmissions to prevent these messages from spreading

Turkish Studies, 15(4) 
seriously around the world is an indication that these messages carry a chain letter form. Unlike past examples, it appears that messages about COVID-19 on WhatsApp are more often spread using the "fear" weapon, prompting recipients to transmit those messages to protect others. It is understood that these contemporary myths, which express danger rather than a promise, are a new and different version of chain letters.

Keywords: chain letters, COVID-19 pandemic, WhatsApp messages, new and different chain letters, contemporary legends.

Öz: Zincir mektuplar, herhangi bir kişi tarafından gönderilen, belirli bir hikâyeyi aktararak alıcıya hitap eden ve alıcının belirli talimatları yerine getirmesini ve kendisine gönderilen içeriğin çoğaltılarak başkalarına gönderilmesini talep eden metinlerdir. Ortaya çıktıkları günden beri birçok farklı form ve muhtevada yazılan zincir mektuplar, alıcılarını "şans ve para, hayır dua, mutluluk, huzur" gibi vaatlerde bulunarak, metnin çoğaltılarak belirli bir süre zarfinda belirli sayıda kişiye gönderilmesini sağlamaktadır. Zincir mektuplar, talimatların yerine getirilmediği durumlarda ise uğursuzluk ve kötü şans getireceği konusunda ihtarda bulunan metinlerdir. Zincir mektuplar, geleneksel yollarla yazılarak dağıtılırken, bilgisayar ve internetin ortaya çıkmasıyla zincir e-postalara evrilmiş, daha sonrasında ise Facebook, Twitter gibi sosyal medya mecralarında sıklıkla paylaşılan zincir mektuplar ortaya çıkmışıı. Zincir mektupların son yayılım alanı ise anlık iletişim uygulaması WhatsApp olmuştur. Çağdaş/kentsel efsaneler olarak tanımlanabilecek zincir mektuplar, internetin hız ve anonimlik imkânlarından da faydalanarak, tarihte hiç olmadığı kadar yaygın bir hale gelmiştir. 2019 yılının sonunda Çin'in Wuhan kentinde ortaya çıkarak küresel anlamda bir salgına dönüşen COVID-19 hastalığının yaşandığı günümüzde, zincir mektuplar için bir zirve bir dönem yaşanmaktadır. Salgının tehlike ve bilinmezliğinden beslenen zincir mektuplar, anlık iletişim uygulaması olan WhatsApp aracılığıyla bütün dünyada çok hızlı bir biçimde kişiden kişiye gönderilir hale gelmiştir. Bu çalışmada, WhatsApp'taki COVID-19 salgınıla ilgili olarak yayılan mesajların, zincir mektupların yeni ve farklı bir biçimi olduğu hipotezinden hareketle, bu uygulamadaki mesajların geleneksel zincir mektuplarla olan benzerliği ve farklıııkları ele alınarak, bu mesajların zincir mektupların yeni ve farklı bir biçimi olup olmadığı incelenmiştir. WhatsApp'taki mesajların ne şekilde zincir mektuba dönüştüğü ele alınarak, bu mecra üzerinde, COVID-19 salgınıyla ilgili yaygın olarak paylaşılan dört ses kaydı ve üç metin mesajı analiz edilerek, yeni nesil zincir mektupların özellikleri ortaya konulmuştur.

Anahtar Kelimeler: zincir mektuplar, COVID-19 salgını, WhatsApp mesajları, yeni ve farklı zincir mektuplar.

\section{Giriş}

Geleneksel bağlamda mektup, tarihin akışı içerisinde bir iletişim vasıtası olarak ortaya çıkmıştır. Şahin Köktürk'e göre mektup, bir anlatım şekli/tekniği ve edebî bir tür olarak, mahrem duygu ve düşüncelerin rahatlıkla ifade edilebildiği önemli bir haberleşme aracıdır (2019: 16). Manzum ve mensur olmak üzere birçok alt başlığı olan mektupların "zincir mektup" gibi farklı bir türü de mevcuttur. Zincir mektuplar (chain letters), herhangi bir kişi tarafından gönderilen, belirli bir hikâyeyi aktararak alıcıya hitap eden ve alıcının belirli talimatları yerine getirmesini talep eden metinlerdir. Anonim olan bu mektupların aslî varoluş sebebi olabildiğince fazla kişiye ulaştırılmalarıdır. İçerdiği halk kültürü unsurları, yaşandığı iddia edilen hadiseler, zaman zaman gerçek kişi ve yer adlarıyla bu metinler, “ya gerçekse?” güdüsünü kullanarak bütün dünyada birçok biçim ve muhtevada yayılmıştır.

1800'lü yılların sonlarında ortaya çıkan zincir mektuplar, alıcıyı kendi nüshalarını (kopyalarını) yapmaya ve dağıtmaya açık bir şekilde yönlendiren; mektubunun biçiminin ve içeriğinin çoğaltılmasıyla, sürekli çeşitlenen; umut ve korku, doğruluk ve hata, sadaka ve açgözlülük gibi farklı teşvikleri kullanarak şans, para, yardımlaşma ve sadaka, hayır dua ve yaşama sevinci gibi çeşitli vaatlerde bulunan bir metindir (VanArsdale, 2002: 1-9). 19. yüzyılın sonlarından itibaren özellikle ABD'de yaygınlaşan ve araştırmacıların dikkatini çeken zincir mektuplarla ilgili ilk araştırmalar 1930'larda başlamıştır (Seljamaa, 2008: 83). Zincir mektupların arkaik örnekleri, 
bin yıldan fazla bir süredir varlığını sürdürmektedir. Öncülleri, eski dualar, şiirler ve büyüler olan zincir mektupların en eski örnekleri, Mısır'daki firavunların mezarlarını süsleyen piramit metinlerinde görünmektedir (Stollznow, 2014: 61).

Linda Dégh, zincir mektupları, "Dünyanın herhangi bir yerindeki gemi kaptanı, doktor veya din adamı gibi kimseler tarafindan başlatılan kaynağı belli (origins) olanlar; bir dua (invocation) ile başlayanlar; mutlu (happy story) ve mutsuz bir hikâyeyi (unhappy story) barındıranlar; sonunda belirli sayıda gönderilme durumunda iyi şans getireceğine dair vaatler içerenler (instruction and promise)" olmak üzere beş sınıfta ele almaktadır (2001: 189-190).

Zincir mektupların olağanüstü bir yayılıma sahip olmasının temel nedeni sihirsel bir gücü ihtiva ettiği iddiasıdır. Birçok farklı muhtevada yazılan zincir mektupların yaygın türlerinden biri, şans ve ödül vaat edenleridir. Herbert Halpert, zincir mektupların ilk bakışta bir "şans zinciri" olarak değerlendirildiğini, mektubun gönderildiği kişinin metni, belirli bir zaman dilimi içerisinde çoğaltarak belirli sayıda kişiye gönderilmesi durumunda güzel bir haber alacağını, şansının artacağını ve para kazanacağını ifade etmektedir (1956: 287-289).

Zincir mektuplar, ödül vaat ettikleri gibi ceza ve uğursuzluk konusunda da ihtarda bulunmaktadır. Alan Dundes'a göre bir metnin zincir mektup olduğunun ilk belirtisi metnin başındaki, diğer folklor ürünlerinin girişinde bulunan başlangıç formellerine benzeyen bir ifadedir. İkinci belirtisi ise, mektubun kopyalarının belli bir süre içerisinde belirli sayıda arkadaş ve tanıdığa gönderilmesi için verilen emirdir. Mektubun alıcısının şartlara uyması durumunda şans ve para gibi sonuçlar ortaya çıkacağı belirtilirken talimatlara uyulmaması durumunda karşılaş1lacak kötü sonuçlar kesin bir dille belirtilmektedir (2007: 422).

Zincir mektuplar, çoğu zaman duygusal bir hikâyeyi elden ele dolaştırırken, insanlardaki acıma duygusunu harekete geçirmektedir. Laura J. Gurak'a göre çoğu zaman aynı özel kalıbı izleyen metin, genellikle ölmekte olan bir kişiyle ilgilidir. Ölmekte olan kişinin son isteğinin reddedilmemesi hususunda ihtarda bulunulur (2001: 89). Çiğdem Kara (2008: 36-42)'nın aktardığ1 örneklerden hareketle; kanser hastası küçük bir kız tarafından gönderildiği iddia edilen ve hayatın doyasıya yaşanmasını tavsiye eden bir hikâye; ömrünün ilerleyen bir zamanında çocuk sahibi olan bir anne veya babanın ölümcül hastalığa yakalanan küçük bebeği ya da altı ay ömrü kalmış bir kişinin yardım talebi gibi hususlar, insanları bu mektupları çoğaltarak göndermek konusunda teşvik edilmektedir. Nefise Abalı'ya göre zincir mektupları saçmalık olarak gören bir birey dahi yalnız kaldığında bu mektubu kişiye hiç üşenmeden birçok kişiye gönderebilmektedir (2008: 69).

Zincir mektuplar ilk etapta yazılı kültür ortamında geleneksel bir biçimde elden ele postalanırken, internetin yaygınlaşmasıyla daha fazla ülkede, daha fazla kişiye ulaşmaya başlamıştır. Trevor Blank (2007: 17) ve Simon Bronner (2009: 38-39)'ın da aktardığ 1 gibi internet öncesi çağda, rastgele adreslere gönderilen ve yayılım bakımından piramit şemasını izleyen zincir mektuplar, internetle sayesinde, genel ağ (web) kullanıcılarının aracılığıyla hızla yayılmaları için anonim bir mecraya kavuşmuştur. Böylelikle zincir mektuplar Walter J. Ong'un ifadesiyle "ikincil sözlü kültür ortamı"na yani elektronik kültür ortamına aktarılmıştır (2013: 161).

Zincir mektupların internet ortamında yayılan ilk formları "zincir e-posta"lardır. Bu epostalar vasıtasıyla alıcı, yalnızca şans için bir mektubu çoğaltarak dağıtan veya bir trajediye üzülen, bu hikâyeyi başkalarıyla paylaşan kişi değil, aynı zamanda bir yardımlaşma kampanyasının da katılımcısı haline gelmiştir. Çiğdem Kara (2008: 39) ve L. L. Campbell (2011: 50) 'in aktardığ1, bu duruma uygun olan örneklerden biri, zincir e-postaların başkalarına iletilmesi durumunda, yardıma ihtiyaç duyan kişilere birtakım kurumlar tarafından bağışta bulunulacağı iddiasıdır. Bu tarz zincir e-postalarda ifade edilen şey tam olarak şudur: Kanser veya bir başka amansız hastalığa yakalanan kimseler tarafından yazılan mektup, oldukça fazla sayıda kişiye iletilirse, hastanın tedavi masrafları "American Canser Society, bazı internet kuruluşları ve hayır kurumları, büyük holdingler ve Bill Gates gibi zenginler”ce karşılanacaktır. Öyle ki bu metinlerdeki içeriğe göre, her 
bir paylaşım, " 0.32 cent" gibi bir maddi değere tekabül edecek ve paylaşım sayısı arttıkça hastalarının tedavisi için yüz binlerce dolar bağış toplanabilecektir. Bu durumda, zincir e-postayı paylaşan kişiler herhangi bir maddi yardımda bulunmamakla beraber, yalnızca yaptıkları paylaşımla, bahsi geçen kişilere yardım edilmesini sağlayabilmektedir. Zincir metinde ifade edilen bu bilgiler 1şığında alıcı, kendisi herhangi bir maddi destekte bulunmasa da oldukça fazla kişiye göndereceği metin aracılığıyla bu yardıma vesile olacak, bir bakıma kendi eylemiyle bu insanların iyileşmesine katkı sağlayacaktır.

\section{COVID-19 ve WhatsApp}

Zincir mektuplar yazılı olarak iletilirken daha sonra internet ortamında zincir "e-posta"lara evrilmiş ve akabinde Facebook gibi sosyal paylaşım ağlarında da "zincir gönderi (chain post)" şekline dönüşmüştür. Piret Voolaid, Facebook’taki zincir mektupların, muhatabı, mektubu kopyalamaya ve belirli bir sayıda veya olabildiğince çok kişiye iletmeye ikna eden bir mesaj oluşturduğunu; gerçek hayattaki (trajik) olaylardan olabildiğince faydalanan bir "newslore" olan bu mektupların paylaşımının, birçok kişi tarafından "beğenildiğini (like)", kişilerin kendi Facebook sayfalarında "paylaşıldığını (share)" ve böylelikle bir "zincir gönderi (chain post)" oluştuğunu ifade etmektedir (2013: 72-75). Zincir gönderilerde de "hasta olan bir küçük çocuk" en çok kullanılan temalardan biri olmakta ve her beğeninin 0.50 cent veya 1 lira, her paylaşımın 1 dolar veya 5 lira bağış anlamına geldiği belirtilmektedir. Bu tarz gönderiler hâlâ Facebook aracılığıyla yayılmaya devam etmektedir.

Yazılı halde postalanan zincir mektupların önce e-postalara oradan da Facebook ve Twitter gibi sosyal medya ağlarına uzanan yayılımının güncel adresi WhatsApp platformudur. Akı1lı telefonlar için anlık bir mesajlaşma uygulaması olan WhatsApp, Kenton O'hara (2014: 1131) gibi araştırmacıların deyimiyle birçok insan için "günlük iletişiminin meskeni" haline gelmiştir. Günümüzde, WhatsApp'ın dünya üzerindeki birçok kişi tarafindan kullanılması, zincir mektupların yayılması için de bir firsat yaratmaktadır. Sırasıyla geleneksel posta, e-posta ve Facebook gibi mecralarda yayılım alanı bulan zincir mektuplar, akıllı telefonların taşınabilirliği ve anlık erişime müsaade etmesi gibi özellikleri sebebiyle, WhatsApp üzerinden kolaylıkla yayılabilmektedir.

2019 yılının sonunda Çin'in Wuhan kentinde ortaya çıkarak bütün dünyaya yayılan COVID-19 salgını, bütün insanlığı ilgilendiren bir hastalık ve tehlike olması sebebiyle, günlük iletişimin en yoğun olarak gerçekleştirildiği WhatsApp'ta da insanların çevreleriyle en çok paylaştığı konulardan birisi haline gelmiştir. Bu çalışmada ele alınan problem, WhatsApp'ta insanlar tarafindan çevreleriyle paylaşılan birçok ses kaydı ve metnin, "zincir mektup"ların güncel ve farklı bir versiyonu olup olmadığıdır. Bu çalışmada, WhatsApp üzerinden gönderilen COVID19 mesajlarının zincir mektupların özellikleriyle uyuşup uyuşmadığı incelenerek, bahsi geçen mesajların zincirleme etkisinin sebepleri ortaya konulmuştur. Bu çalışmada ileri sürülen "WhatsApp'ta paylaşılan COVID-19 salgını ile ilgili mesajların zincir mektupların yeni ve farklı bir biçimi" olduğu hipotezi, veriler 1şığında değerlendirilmiştir.

\section{WhatsApp ve Zincir Mektuplar}

Toplumsal hayatta iz bırakan olayların yaşandığı korku ve kaos dönemleri, karmaşanın etkilerinden beslenen efsanelerin doğuşuna sebebiyet verir. Zaman içerisinde böylesi efsanelerin ortaya çıkış şekilleri unutulsa da efsaneler yaşamaya devam eder. Toplumu etkileyen hadiseler modernite döneminde yani yakın bir zamanda yaşandıysa, bu hadiseler, "kent efsaneleri"ni yani "çağdaş efsaneler"i meydana getirir.

Pedro Sebastião'ya göre kentsel efsaneler, insanların neredeyse tanıdığ bir kişinin hissettiği veya tanık olduğu gerçek hadiselerden beslenerek inanılan anlatılar olarak, sıradan efsanelerden ayrılırlar. Gerçek ve yakın zamandaki olaylar çerçevesinde anlatılan bu efsaneler, genellikle anlatıcıların çevresindeki yer veya varlıkların adlarını içermektedir (2010: 4). Linda Dégh'in ifadesiyle insan, "homo religious"dur. İnanmak, insanın doğasında vardır (1996: 35). Bu 
sebeple insan, dışarıdaki dünyadan etkilenmeye, efsaneler üretmeye ve inanmaya devam etmektedir. Rolf W. Brednich, çağdaş efsanelerin, modern kitle iletişim araçları tarafindan büyük ölçüde desteklense de, temel olarak sözlü geleneğe ait olduğunu ve modern teknik dünyada bile yüzlerce öykünün hâlâ ağızdan ağza aktarıldığını ve varlıklarını sürdürdüklerini belirtmektedir (2002: 7).

Zincir mektuplar, bir bakıma modern zamanın çağdaş efsaneleridir. Bu mektuplarda anlatılan anonim hikâyeler, toplumda karşıllk bulmakta ve şifahî olarak anlatılmanın yanı sıra büyük oranda kitle iletişim araçları yoluyla aktarılmaktadır. Bu çağdaş efsaneler günümüzde, WhatsApp üzerinden de insanlara ve onların çevrelerine yayılmaktadır.

2019 yılının sonunda Çin'in Wuhan kentinde ortaya çıkan COVID-19 hastalığ1 küresel çapta bir salgına dönüşerek, bütün insanlık için tehdit haline gelmiştir. Bütün dünyada yetkililer bu hastalıkla ilgili sosyal mesafeyi sağlamak ve insan hareketliliğini asgariye düşürmek gibi temel önlemlerle hastalığın yayılım hızını düşürmeye çalışmaktadır. Dünyanın dört bir yanından gelen salgınla ilgili haberler, insanların ana gündem maddelerinden biri haline geldiğinde, insan iletişiminde hastalıkla ilgili olan konuların sayısı artmış ve WhatsApp gibi iletişim araçlarında kaynağı belirsiz haber ve ses kayıtları yayılmaya başlamıştır.

WhatsApp üzerinden yayılan COVID-19 mesajları da bu çağdaş efsanelere yani zincir mektuplara örnek olarak gösterilebilir. Bu anlık mesajlaşma uygulaması üzerinden yayılan zincir mektuplar, inandırıcılık etkisi ve dünyanın tamamında büyük yankılara sebep olduğundan, WhatsApp yöneticileri tarafından, aynı anda iletilebilen mesajların sayısı sınırlandırılmıştır ${ }^{1}$.

WhatsApp'ta özellikle "lütfen dikkat, uyarı, kulak ver" gibi ifadeler içeren sözlü veya yazılı bilgilendirme mesajları s1klıkla gönderilmektedir (Resende and others, 2019: 229-231). Bu tarz mesajlar özellikle insanların kayıtsız kalamadığı salgın bir hastalıkla ilgili olduğunda, daha fazla dikkat çekmekte ve başkalarıyla paylaşılmaktadır.

Salgın hastalığın küresel çapta yayılmaya başladığı günlerde, bütün dünyada olduğu gibi Türkiye'de de toplumda korku yaratan birçok ses kaydı ve yazılı mesaj özellikle WhatsApp üzerinden aile, arkadaş çevresi ve akrabalar arasında yayılmaya başlamıştır. Salgının başlangıç dönemlerindeki WhatsApp mesajları daha çok, hakkında pek fazla şey bilinmeyen bu hastalığın ortaya çıkış nedenleri ve henüz yetkililer tarafından bu yönde bir açıklama yapılmamasına rağmen, hastalığın Türkiye'de de görüldügü iddiaları ileri sürülmüsstür.

Türkiye'de, hastalığın Çin'deki durumunun dünya kamuoyundan gizlendiğini anlatan, WhatsApp gruplarında, insanların yakın çevresi arasında en çok paylaşılan ses kayıtlarından biri şu şekildedir:

"Tayfalar şimdi bir arkadaşımla telefonla konuştum, motorcu bu. Ŏğlu şu an Guangzhou'da yüksek ihtisas yaptyor, top doktoru, genel cerrahide. Öyle haberlerde duyduğunuz gibi değilmiş olay. Şu an 25 milyon enfekte varmış. 40.000 civarı da ölü varmış. $O$ virüsün çıktı̆̆ını söyledikleri şehirde, sokakların bomboş olmasının sebebi, ölenlerin çok fazla olmasındanmış. O bölgede çok tüketilen bir yılandan bulaştığııı düşünüyorlarmış ve o yılanın yetiştiği su birikintisinin içinde de bir kalıntılar bulmuşlar, füze kalıntıları gibi. Yani biyolojik saldırı olduğunu düşünüyormuş Çin hükümeti. Olay biraz ciddi boyutlara geliyor. Ayn zamanda, bu biyolojik silah olduğunu düşündüğ̈̈nden dolayı da saldırının gelebileceği yerlere özellikle ajanları gönderip enfekte ettirmiş Çin. Dolayıslyla dünyaya çok kisa sürede yayllacağını düşünüyorlarmış. Bir de bilinen tüm virüslerin formlarından farklyymıs virüs. Girdiği vücuttaki bütün bakteri ve virüslere bir mutant gibi yerleşip onlart aktive ediyormuş. Onun için de şu an nasıl çözeceklerini bilmiyormuş bilim adamları. Insanlar çalışmaya başlamışlar ama zannedersem bayağı bir zaman kalacakmış. Çocuğun direkt babasına

\footnotetext{
${ }^{1}$ URL-1
} 
söylediği şeyler bunlar. Kesin doğru yani. Bilginiz olsun. Dikkatli olun. Muhtemelen Türkiye'de de var bu virüs. Onun için çok dikkatli olmak lazım²."

WhatsApp'ta dolaşan, COVID-19 salgınıla ilgili zincir mesajlar alıcılarını korku ekseninde uyararak, harekete geçmelerini sağlamaktadır. Mesajların içeriğinde yer alan gerçeğe yakın bilgiler de mesajların güvenilirlik etkisini artırmaktadır. Araştırmacıların (Seljamaa, 2008: 83; Kara, 2008: 48; Stollznow, 2014: 61) da belirttiği gibi, zincir mektupların gerçek olma olasılı̆̆ının göz önünde bulundurulmasında, açıkça kullanılmış ad ve adresler de etkili olmaktadır. Bunlar, aktarılan olayın gerçeklik imajını güçlendirmektedir. Aşağıdaki örnekte anlatılan hikâye de tam olarak böyledir.

\title{
“Evet, arkadaşlar. Alibey Hospital'da altı tane vaka yakalanmış, koronavirüsünden dolayı. Su anda faal aslinda. Birazdan ambulanslar sira sira gelecek. Karantina altina alacaklar tahmin ediyorum. Lütfen, vatan, millet sağ olsun. Devletimiz ne yapacak bu konuda, nasll çözeceğiz bilmiyorum ${ }^{3}$.“
}

WhatsApp'ta yayılan zincir mektupların geneli, Türkiye'de COVID-19 hastalı̆̆ının görülmediği tarihlerde, bu hastalığın görüldüğüne dair bilgileri yaymaktadır. Alıcıları tedirginliğe sevk etmek yoluyla, mesajların daha fazla kişiye yayılması sağlanmaktadır. Aşağıdaki örnekteki zincir mektup, yine insanları korku ile güdüleyerek, paylaşılmasını sağlamaktadır.

\begin{abstract}
“Arkadaşlar iyi akşamlar. Ben, Deniz Nisa'nın annesi. Bugün bir müşterim geldi. Acıbadem'de hemşire. Maalesef koronavirüsü Maslak, Acıbadem'e kadar gelmiş durumda ve Istanbulda pek çok hastane karantina altında ancak yasaklı oldukları için açıklama yapılmıyor. Kendisi bizzat bize korunmamız için maske de getirmiş săg olsun. Sizlerden ricam, yakında ortaya çıkacak bu ve on beş gün İstanbul'da okullar tatil edilecek. Dezenfekte yapılmak amaçlı. Mümkün mertebe alışveriş merkezlerine gitmemeniz, toplu taşımaları kullanmamamı gerekiyor. Kullansak bile dezenfekte olmamı gerekiyor ve maskeyle dolaşmamı gerekiyor. Buna istinaden şöyle bir şey de olacak diyorlar, bu da kesin ve net bir bilgidir. Sizlerle de paylaşmak istedim. Marketlerden, mümkün olduğu kadar evlerinize stok yapın çünkü yakında bildiğimiz bir yağmalama olacak çünkü insanlar artık dışarı çıkamaz hale gelecekler. Çünkü bu virüs, bayă̆l ciddi bir olaya mutabık herkesin bildiği gibi. Şu an açıklanmıyor ama İstanbul'da birçok ölü var. Özellikle Ümraniye Ĕ̈itim Araştırma Hastanesi'nde de böyle vakalar var. Doktor ve hemşire tanıdıklarım olduğu için bu bilgilere ulaşabildim. Zaten yakında televizyonda haberlerde göreceksiniz. Şu an halk panik yapmasın diye kimse bunu paylaşmıyor sizlerle. Ne bileyim işte makarnanızı, fasulyenizi, pirincinizi, ununuzu, bunlarl alıp stok yapın arkadaşlar. Çünkü yakında marketlere gidemeyeceğiz. Biz şimdiden başladık bunlarl ailecek yapmaya. Sizleri de bilgilendirmek istedim. Lütfen kulak arkası yapmayın, sonradan pişman olmayalım ${ }^{4}$."
\end{abstract}

Her ne kadar zincir mektuplar siber uzayın hız ve erişim gibi bütün özelliklerini devreye soksa da anonim oluşu özellikle kayda değerdir. Hiç kimse bir mesaj1 yazarına kadar takip edemediğinde, yazarlar aksi takdirde yapamayacakları şeyleri yapmaktan ilham alırlar (Gurak, 2001: 102). WhatsApp'taki zincir mektupların ilk göndereni, ancak ilk çemberdeki alıcılar tarafından tespit edilebilirken, mesajlar yayıldıkça, anonim hale gelmekte ve ilk gönderici tespit edilememektedir.

Bazı zincir mektuplarda anlatılan hikâye, okuyucu veya dinleyiciyi, mesajın doğruluğu konusunda reddedilemeyecek bir algıya sürüklemektedir. Bu tarz mesajlarda, aktarılmak istenen bilgiye inanmadığ görünmektedir. Böylelikle, mesaja dair bir doğrulama, yine aynı gönderinin içerisinde yer

\footnotetext{
${ }^{2}$ URL-2

${ }^{3}$ URL-3

${ }^{4}$ URL-4
} 
almaktadır. Aşağıdaki ses kaydında, mesajı aktaran kişinin kocası da duruma ilk başta inanmamakta ancak daha sonra eşinin haklı olduğuna kanaat getirmektedir.

\begin{abstract}
"Devlet hastanesinde, Ümraniye Eğitim Araştırma Hastanesi'nde yardımcı olduğumuz bir insan var öyle söyleyeyim. Direkt şu anda aradım, dedim böyle böyle, sana bir şey soracağım. Dürüst davran bana. Böyle böyle bir durum var mı? Orada çalışlyor. Doktor değil ama çalışanlardan biri. Ümraniye Ë̆itim Araştırma'ya gelen biri var mı? Bana duyduğun bir şey söyleme sakın dedim. Yaşadığın bir şey var mı dedim koronayla ilgili. Zeynep Hanım, bana çok iyiliğiniz dokundu dedi fakat bu bilginin benden çıktı̆̆ anlaşllırsa ben işimden olurum. Kendi iç hastane grubumuzun içinde çok ciddi bir bask var dedi. Ben sana dedim hiçbir şekilde benden sana zarar gelmez dedim. Hastane, bir hafta önce hastanede kırmızı alarm verilmiş. Çocuk kendisi anlatıyor, bu bir yerden duyma falan değil. Zeynep hanım ne olur dikkat edin, tedbir alın diye çocuk bana yalvariyor. Ne olur aramıda kalsin diyor, isim vermeden söyleyin, sadece Türkiye'de görülmü̈ş deyin. Bir hafta önce kırmızı alarm verilmiş. Bir kadın. Karantina odaları varmıs bunların, oraya alınmıs. Ondan sonra kadın öldü mü kaldı mı, hastane içinde çalışanlara bile bilgi vermiyorlar, üstü kapatılmış. Odanin oraya gitmek de yasak. Bir de sistemlerinin ortak bir ekranları varmıs devlet hastanelerinin. Mesela belli bir bölgenin, attyorum, Ümraniye, Sancaktepe, işte bilmem, Ataşehir, Sultanbeyli, bu bölgenin ortak bir ekranı varmış. Mesela bilmem, Pendik, Göztepe, Maltepe, oraların bir ortak ekranı varmış. Bu ortak ekranda, hastanede ölenlerin ölüm saati, tarihi ve ölüm nedeni ekrana giriliyormuş. Bu çocuk kendi gözüyle, on beş gün önce, bilmem şu şu, ölüm sebebi koronavirüs diye gözüyle görmüş arkadaşlar. Artık bunun abartmak, bilmem ne, hurafelik bir tarafi yok. Sadece dikkat olalım, dikkat edelim, sadece çocuklarımızı koruyalım, kendimizi koruyalım. Ben bu çocuğu şunun üzerine aradım. Ali bugün bana dedi ki, eşim ki çok sakin o normalde. Zeynep, az önce, dedi. Karşıdaydl onlar Bakırköy tarafinda. Yanımızdan bir ambulans geçti, dedi. Yanımızda birazcık yavaşlayınca gördüm içini, ben sana kizlyordum birazclk abartlyorsun diye ama ambulansın şöförü ve yanındaki hemşire dedi, o koronavirüs klyafetleri var ya beyaz, onlarlayd dedi. Ali söyledi yani kocam. Bunu hiçbir yerde basında görmedim, duyum değil, bir şey değ̈il, inan dedi, çok haklyymışsın, ben de şoka girdim dedi. Arkadaşlar, şu anda Türkiye'de bangır bangır koronavirüs var. Sadece mevcut siyasi durumdan dolayl saklamayı şey yapıyorlar demek ki. Bu şekilde baş edemezler, halkı bilinçlendirseler çok daha faydalı olacak bu. Lütfen bu sesli mesajı da tanıdıklarınıza gönderin, edin ${ }^{5} . "$
\end{abstract}

Zincir mesajların en büyük beslenme kaynakları belirsizlik durumları olarak görülmektedir. Özellikle bütün toplumu alakadar eden hadiselerde, ortada bir belirsizlik durumu söz konusu ise, zincir mektupların alıcılara daha inandırıcı gelmesi, yayılma hızlarından anlaşılmaktadır.

WhatsApp'ta, COVID-19 salgınıyla ilgili dolaşan ses kayıtları dışında, yazılı mesajlar da sıklıkla gönderilmektedir. Yazım ve imlasına sadık kalınarak verilen mesajlardan biri, sirkenin koronavirüsü öldürebileceğine dair bir iddiayı ileri sürmektedir:
“Arkadaşlar Türkiye ye girmiş bulunan Korona virüsü 24 saatte öldürüyormuş.Ve tek pan zehiri ÜZÜM SïRKESİ imiş. Lütfen evlerinizi temizlerken kovaya bir çay bardağ üzüm sirkesi ilave edin. Aynı işlemi bulaşık makinası ve çamaşı makinasında da yapacağız. Çok çok önemli. İhmal etmeyin ve bu mesajı yayabildiğiniz kadar yayı" "."

Bir başka mesajda, su buharının koronavirüsü öldürebileceği ifade edilmiştir.

“Çinli bir uzman, sıcak sudan buhar solunmasının Corona virüsünü yüzde 100 öldürdüğünü herkese garanti ediyor. Virüs Burun, boğaz veya Akciğerlere girse bile

\footnotetext{
${ }^{5}$ URL-5

${ }^{6}$ URL-6
} 


\section{Corona Virus sicak su buharına dayanamiyor... LÜTFEN BU BİLGiLERİ TÜM AILE ÜYELERINIZ VE ARKADAŞLARINIZA DOLAŞIN”." “}

Aşağıdaki zincir mektupta, yerel yönetimler veya yetkililerce herhangi bir açıklama yapılmamasına rağmen, Antalya şehrinin ilaçlanacağını ileri sürmüştür.

\section{"Antalya için Bu akşam saat 23.30 kimse dı̧̧arıda bulunmasin uyarısı yapıldd. Kapıların, Pencerelerin. Kapalı kalmast gerekiyormuş.. Korona virüs için 5 helikopter Dezenfektan ilaçlaması Yapılacakmış. Lütfen bu Mesajı arkadaşlarınıza çevrenizdekilere bu bilgiyi Paylaşın.... ."}

Bilgisayarlarda yapılan hesaplama ve simülasyonlar göstermektedir ki zincir mektuplar, sonsuz bir yayılım döngüsüne sahiptir (Nahin, 2014: 70-71). Postalanma amacı ne olursa olsun, mektubun yayılabilmesi ve uzun süre de dolaşımda kalabilmesi için içeriğinin doğru bir biçimde kodlanması ve uygun, "doğru" aktarıcılara ulaştırılması yeterlidir (Kara, 2008: 49). COVID-19 salgınıyla ilgili zincir mektuplar daha çok "hastalığın kaynağı, kaç kişiye bulaştığı, ölüm sayıları, bir ülkede görülüp görülmediği ve hastalığa karşı kullanılabilecek unsurlar" olarak kodlanmıştır.

Linda Dégh'e göre efsane, herhangi bir kişiden bir diğerine, herhangi bir şekilde aktarılan geleneksel ya da geleneksel olmayan hikâyedir. Gerçek olsun veya olmasın, anlatıcı ve dinleyicileri tarafından gerçek olduğuna inanılır (2014: 206-207). Zincir mektuplar da inandırıcılığı olan çağdaş/kentsel efsanelerdir. Marjorie D. Kibby, kentsel efsanelerin, çağdaş toplumun korkularını ve takıntılarını yansıtan "korku folkloru (scarelore)" olarak görülebileceğini ifade etmektedir (2005: 779-782). Blank'a göre sözlü olarak iletilen kentsel efsaneler, kodlanmış dilde toplumsal korku ve önyargıları ifade ederken, elektronik olarak iletilen kentsel efsaneler, gönderenin anonimliği nedeniyle toplumsal korkuları ve önyargıları daha aşındırıcı bir şekilde ifade eder (2007: 19).

\section{WhatsApp'ta Dolaşan Zincir Mektupların Ortak Özellikleri}

WhatsApp'ta dolaşan, COVID-19 salgınıyla zincir mektuplar da çağdaş/kentsel efsaneler olarak değerlendirilebilir. Bu çağdaş efsaneler, gerçek kişi, yer ve olaylara atıfta bulunmak suretiyle toplumun korku duygusunu körükleyerek yayılmaktadır. İlk göndericinin bilinmesi mümkün olmayan zincir mektupların, belirli ortak özelliklere sahip olduğu tespit edilmiştir. Bunlar:

Güncel bir tehlike veya sorunla ilişkili olması,

Korku ve hayatta kalma içgüdüsünü tetiklemesi,

Başkalarını koruma isteği,

Mesajın göndericisinin, aile veya arkadaş çevresinden olması,

Alıcıların, göndericinin mesajı mantıklı bulduğunu düşünerek fikir birliği içerisine girmesi,

Gelen mesajı başkalarına yaymanın toplumsal bir sorumluluk olarak görülmesi,

Zamanla ilk gönderici belirsizleştiği için mesaj anonim hale gelse de ileticinin kimliğinin açık olması ve iletenle alıcının karşılıklı ilişki halinde olması.

WhatsApp'ta dolaşan COVID-19 zincir mektuplarıyla, yazılı veya e-posta aracılığıyla gönderilen zincir mektuplar arasında belirli farklar da dikkati çekmektedir. Öncelikle geleneksel zincir mektuplar, "şans, para, dua, amansız hastalığa yakalanan birinin son isteğini yaymak, hasta bir kişiye yardım etmek" gibi kodlarla ilintilendirilerek gönderilirken, koronavirüs ile ilgili WhatsApp zincir mektupları daha çok "salgınla ilgili bir gerçekliği paylaşmak, gizlenen gerçekleri

\footnotetext{
${ }^{7}$ URL-7

${ }^{8}$ URL-8
} 
gözler önüne sermek, insanları uyarmak, salgının bir ülkeye giriş yaptığını bildirmek ve bu salgından korunmaya yarayacak önlemleri aktarmak" kodlarıyla işlenmiştir. Bunun yanı sıra alıcilara gelen mesajlarda hem geleneksel zincir mektuplar hem de WhatsApp'ta yayılan zincir mektuplar "lütfen, dikkat, sevdiklerinize gönderin, herkese yayın, duyarsız kalmayın" gibi rica kabilinden sözleri içermektedir. Geleneksel zincir mektuplardaki hasta bir çocuğa yardım veya mektubun çoğaltılarak başkalarına gönderilmesi durumunda gelecek şans veya aksi taktirde uğursuzluk getireceğiyle ile ilgili uyarılar, WhatsApp'taki zincir mektuplarda bulunmamaktadır. Ayrıca, yeni nesil zincir mektuplarda, mektubun belirli bir süre içerisinde iletilmesi gerektiği talimatı da yer almamaktadır. Yeni nesil zincir mektuplar, insanları daha çok korku ekseninde harekete geçirmektedir. Geleneksel zincir mektuplardaki "ölmekte olan bir kişinin son sözlerini yayma, hasta bir çocuğun tedavi masraflarının karşılanması için mektubu iletme, çoğaltılan mektubun şans ve para getireceği" gibi vaat ve talimatlar yerini mutlak "korku"ya ve sevdiklerini koruma içgüdüsüne bırakmıştır.

WhatsApp'ta dolaşan COVID-19 mesajlarının yayılımı, küresel anlamda ciddi boyutlara ulaştığı için şirket yetkilileri, mesajların iletimine sınır getirmiştir. WhatsApp, ilk etapta, sınırsız sayıda mesaj iletimini engelleyerek, bir mesajın aynı anda en fazla beş kişi veya gruba iletilebileceğini belirtmiştir. Daha sonra iletim sayısı en fazla bir mesajla sınırlandırılmıştır ${ }^{9}$. Gurak (2001: 104)'ın da ifade etiği gibi, “internet aracılığıla herkes bir yazar, okuyucu ise bütün dünya"dır. Bu bakımdan, COVID-19 mesajları, internette ve özellikle WhatsApp'ta, anonimlik maskesinin ardına gizlenilerek rahatlıkla gönderilebilmektedir. Bununla beraber, COVID-19 ile ilgili mesajların diller arasında tercüme ve yeniden şekillendirmeler yoluyla yerelleştirildiği de görülmektedir.

\section{Sonuç}

Zincir mektuplar, 19. yüzyıldan günümüze kadar gelen, çeşitli konularda insanların farklı hassasiyet noktalarına temas ederek yayılan metinlerdir. Teknolojinin gelişmesiyle beraber yeni yayılma alanları bulan zincir mektuplar, yazılı ortamdan, internetle beraber ikincil sözlü kültür ortamına aktarılmış ve daha büyük yayılma hızı kazanmıştır. Tarihi serüveni boyunca geleneksel mektuplardan e-postalara, oradan Facebook, Twitter gibi sosyal medya vasitalarına aktarılan zincir mektuplar, son olarak anlık mesajlaşma uygulaması WhatsApp aracılığıyla yayılmaya başlamıştır.

COVID-19 salgını gibi bütün dünyanın etkilendiği ve haber almanın büyük önem arz ettiği son zamanlarda, zincir mektuplar, daha önce olmadığı kadar büyük bir yayılım ortamı bulmuş ve COVID-19 salgını ile ilgili belirsizliklerin had safhaya çıktığı bir dönemde bütün dünyaya yayılmıştır. Ortaya çıktığı tarihlerden itibaren, kademeli bir şekilde çoğalan zincir mektuplar, geleneksel bir mektup formunda yayıldığı kısıtlı alandan, e-posta kullanıcıları gibi internet ve bilgisayar erişimi olan kimselere; oradan Facebook ve Twitter gibi küresel sosyal medya mecrasına ve son olarak da bir akıllı telefon ve WhatsApp uygulaması kullanan, dünyanın her yerindeki insanlara yayılma imkânı bulmuştur.

Bu çalışmada, WhatsApp'taki COVID-19 salgınıyla ilgili mesajların, zincir mektupların yeni ve farklı bir biçimi olduğu iddiasından hareketle, bu mecrada yayılan dört ayrı ses kaydı ve üç farklı metin ele alınarak incelenmiştir. WhatsApp'ta yayılan ses kayıtları ve metinlerinin, geleneksel zincir mektuplarla ortak ve farklı özelliklere sahip olduğu tespit edilmiştir. Çağdaş efsaneler olarak tanımlanabilecek zincir mektupların, güncel ve bütün dünyayı ilgilendiren bir salgın hastalıktan ne şekilde beslendiği ve yayıldığı görülmüştür. WhatsApp şirketinin, bütün dünyada ciddi şekilde yayılan bu mesajları engellemek için mesaj iletim sayılarını sınırlaması da bu mesajların zincir mektup formu taşıdığının bir göstergesidir. Geçmişteki örneklerinden farklı olarak, WhatsApp'taki COVID-19'la ilgili mesajların daha çok "korku" silahını kullanarak yayıldığı ve alıcıları başkalarını korumak adına bu mesajları iletmeye sevk ettikleri görülmektedir.

\footnotetext{
${ }^{9}$ URL-9
}

Turkish Studies, 15(4) 
Bir vaatten ziyade tehlikeyi ifade eden bu çağdaş efsanelerin, zincir mektupların yeni ve farklı bir versiyonu olduğu anlaşılmaktadır.

\section{Kaynakça}

Abalı, N. (2008). Zincir Mektupların Jung’un Bilinçdışının Dinsel İşlevi ve Arketipleriyle Okunması. Millî Folklor, 79 (20): 65-69.

Blank, T. J. (2007). Examining the Transmission of Urban Legends: Making the Case for Folklore Fieldwork on the Internet. Folklore Forum, 37.1: 15-26

Brednich, R.W. (2002). Where They Originated. Some Contemporary Legends and Their Literary Origins. Folklore: Electronic Journal of Folklore, 20: 7-16.

Bronner, S. J. (2009). Digitizing and Virtualizing Folklore. In Folklore and The Internet: Vernacular Expression in A Digital World, Ed. Blank, Trevor J.. Logan: University Press of Colorado. pp. 21-66.

Campbell, L. L. (1911). Endless Chain Letters. AJN The American Journal of Nursing, 12(1): 50.

Dégh, L. (1996). What Is A Belief Legend? Folklore, 107: 33-46. from www.jstor.org/stable/1260912

(2001). Legend and Belief: Dialectics of A Folklore Genre. Bloominghton Indiana University Press.

------- (2014). Günümüz Bağlamında Efsane Üzerine Teorik Bir Düşünme ve Efsanenin Tanımı. Çev. Selcan Gülçayır, Halkbiliminde Kuramlar ve Yaklaşımlar, 2. Ankara: Geleneksel Yayınları.

Dundes, A. and Bronner, S. J. (2007). The meaning of folklore: The analytical essays of Alan Dundes. Logan: Utah State University Press.

Gurak, L. J. (2001). Cyberliteracy: Navigating the Internet with Awareness. New Heaven: Yale University Press.

Halpert, H. (1956). Chain Letters. Western Folklore, 15: 287-289.

Kara, Ç. (2008). Zincir Mektuptaki Ölümsüz Kanser Hastası Çocuk. Millî Folklor, 77 (20): 35-49.

Kibby, M. D. (2005). Email Forwardables: Folklore in The Age of The Internet. New Media \& Society, 7(6): 770-790.

Köktürk, Ş. (2019). Halkbilimi Araştırmaları I. Ankara: Merdiven Yayınları.

Nahin, P. J. (2014). Will You Be Alive 10 Years from Now?: And Numerous Other Curious Questions in Probability. Oxford: Princeton University Press.

O'Hara, K. P. and others (2014). Everyday Dwelling with WhatsApp. In Proceedings of the 17th ACM conference on Computer supported cooperative work \& social computing (pp. 11311143).

Ong, W. J. (2013). Sözlü ve Yazılı Kültür Sözün Teknolojileşmesi (Çev. Sema Postacıŏlu Banon). İstanbul: Metis Yayınları.

Resende, G. and others (2019). Analyzing Textual (mis) Information Shared in WhatsApp Groups. In Proceedings of The 10th ACM Conference on Web Science (pp. 225-234). 
Sebastião, S.P. (2010). Urban Legends and New Media: Postmodern and Technological Changes in Traditional Stories. Literature, Art, and Culture in an Age of Global Risk, Cardiff University. from https://ssrn.com/abstract=1694488

Seljamaa, E. H. (2008). Remarks on The Historic-Geographic Method and Structuralism in Folklore Studies: The puzzle of chain letters. Journal of Ethnology and Folkloristics, 2(1): 83-98.

Stollznow, K. (2014) Chain Letters. In: Language Myths, Mysteries and Magic. Palgrave Macmillan, London.

VanArsdale, D. W. (2002). Chain Letter Evolution. From http://www.silcom.com/ barnowl/chainletter/evolution.html

Voolaid, P. (2013). Click 'Like' and Post It on Your Wall! Chain Posts on Facebook-Identity Construction and Values. Folklore: Electronic Journal of Folklore, 53: 73-98.

\section{İnternet Kaynakları}

URL-1: "WhatsApp'ta Mesaj Paylaşımı Zorlaşıyor". https://www.dw.com/tr/whatsappten-mesajpayla\%C5\%9Fmak-zorla\%C5\%9F\%C4\%B1yor/a-53046895 (Erişim Tarihi: 11.05.2020).

URL-2: "Ses Kayd1 I". https://www.gzt.com/video/jurnalist/whatsapptan-yayilan-coronaiddialarini-analiz-ettik-2184498 (Erişim Tarihi: 11.05.2020).

URL-3: "Ses Kaydı II". https://www.youtube.com/watch?v=2CzD3nPlHeA (Erişim Tarihi: 12.05.2020).

URL-4: "Ses Kaydı III". https://www.youtube.com/watch?v=DftAqYqL2MY (Erişim Tarihi: 13.05.2020).

URL-5: "Ses Kayd1 IV". https://www.youtube.com/watch?v=9GMLsTYrdKI (Erişim Tarihi: 12.05.2020).

URL-6: “Üzüm Sirkesinin Koronavirüsü Öldürebileceği Mesaj1”. https://teyit.org/koronavirusunpanzehirinin-uzum-sirkesi-oldugu-iddiasi/ (Erişim Tarihi: 09.05.2020).

URL-7: “Antalya Şehrinin Havadan Dezenfekte Edileceği Mesaj1”. https://teyit.org/sehirlerinkoronaviruse-karsi-helikopterlerle-dezenfekte-edilecegi-iddiasi/ (Erişim Tarihi: 07.05.2020).

URL-8: "Buharın Koronavirüsü Öldürebileceği Mesajı”. https://teyit.org/buhar-solumanin-covid19u-tedavi-ettigi-iddiasi/ (Erişim Tarihi: 07.05.2020).

(URL-9: "WhatsApp'ta Mesaj Paylaşımının Bir Mesajla Sınırlandırılması". https://www.aa.com.tr/tr/dunya/whatsapp-mesaj-iletimini-sinirlandirdi/1795563 (Erişim Tarihi: 30.05.2020). 